\title{
Microscale Walkability Modelling. The Case of Athens City Centre
}

\author{
Alexandros Bartzokas-Tsiompras*, Yorgos N. Photis \\ Department of Geography and Regional Planning, A National Technical University of Athens, 9 Iroon Polytechneiou Str., \\ Zographos 15780, Greece
}

Corresponding Author Email: abartzok@mail.ntua.gr

https://doi.org/10.18280/ijsdp.160302

Received: 6 January 2021

Accepted: 20 May 2021

\section{Keywords:}

walkability, urban transport, city center, Athens, built environment

\begin{abstract}
To date, several macro-level walkability measures have been proposed, but microscale and audit-based walkability approaches prove to be highly effective to support realistic, quick and cheap mechanisms for pedestrian-friendly environments. Yet, walkability audits are time- and cost-intensive solutions, because they require several streetscape observations. This study aims to investigate whether a multiple linear regression model of urban form- and function-related variables can effectively predict an audit-based average walkability indicator. For this purpose, we use a virtual, brief and reliable audit tool (MAPS-Mini) in Athens city centre in order to collect street-level data and in turn to construct a microscale walkability indicator (dependent variable). Moreover, our approach suggests a flexible statistical model of open-source data, with six exploratory variables of the macro-level built environment: angular integration, population density, transit stop density, pedestrian street density, retail and entertainment activity density, and building height. The results indicate that audit-based average walkability scores can be effectively estimated, as the regression model can explain about $82 \%$ of the variation. Furthermore, the density of retail and entertainment activities was indicated as the strongest correlate of more walking-friendly streetscapes, while some urban policy implications include the promotion of footpath repairs and better-engineered crossings.
\end{abstract}

\section{INTRODUCTION}

Community design attributes for active travel are broadly classified into two categories. Firstly, the macroscale, incorporating features of neighborhood structure, such as street layouts, population dynamics, or land use patterns, and secondly the microscale, consisting of detailed characteristics about the sidewalks, aesthetics, crosswalks, etc. [1]. In general, macroscale features support active travel feasibility, while microscale attributes affect the desirability for walking. Yet, both types of neighborhood design factors can explain walking [1-6], and many of them have been used to operationalize the concept of walkability [7].

However, macroscale variables of walkability concepts are by far more popular in research studies, since they require data that are already incorporated in local GIS databases (e.g., land use mix, population density, intersection density). On the other hand, microscale environmental features are more popular in daily policymaking, as they require cost-effective and realistic solutions than transforming the macro-level environment [1, 6]. Additionally, previous research has shown that microscale walkability concepts are suitable tools to measure activityfriendly places and to support planners in designing healthier and livable communities [1,8]. Still, microscale variables present challenges in data collection, as they require systematic observation of pedestrian streetscapes and in turn require a time-consuming and labor-intensive research protocol [9]. For instance, Day et al. [10] reported that a 160item list of a street observation instrument required about 20 minutes of fieldwork per segment.
Therefore, to avoid extensive street-level data collection processes more research is required to explore the construction of simple microscale walkability prediction models. In this framework, this study aims to construct a micro-level walkability index for Athens central urban area and then to regress the average values of the index using free and opensource macro-level environmental correlates of walking. Therefore, an effective regression model can support planners and public health practitioners in strategic planning for healthier transportation systems and communities.

Section 2 presents the relevant literature. Section 3 introduces background information about the study area. Section 4 elaborates on the methodological framework and the data variables. Section 5 provides the statistical and spatial analysis results of the micro-level walkability index. Section 6 includes the discussion, and Section 7 presents the conclusion.

\section{LITERATURE REVIEW}

Walkability studies was first initiated in urban planning in the 1990s, when neighborhood characteristics started to be related to active travel, and since then they have been acknowledged as a central aspect of planning more sustainable, and healthy neighborhoods $[1,4-6,11]$.

However, there is no global consensus on a universal and standard protocol in walkability instruments [7, 12-14], and several measurement approaches have been proposed in the fields of health or environmental sciences [12]. The conventional macro-level and objectively measured 
walkability approach is actually the most popular technique in many health and transport planning studies [12], since it usually requires common geospatial data stored in primary GIS databases. Practically, macro-level walkability indicators employ simple spatial analysis techniques to aggregate various structural measures of urban morphology and access, so as to help researchers and professionals to explore car-dependent communities across an urban region, or to investigate the influence of built environment on physical activity. A popular approach to macro-scale analysis of walkability is the work of Frank et al. [4], who built up a walkability index based on the aggregation of three standardized geospatial variables, i.e., net residential density, street connectivity, and an entropy indicator for land-use mix. Using this composite measure, they found that persons living in the highest walkability quartile are 2.4 times more likely than those in the lowest quartile to engage in more than 30 minutes of moderate physical activity per day [15]. Similar approaches utilizing various (weighted [16] or unweighted) combinations of density [17], connectivity [18], and accessibility metrics have also been proposed for walkability analysis [12], and the outcomes of these approaches with walking for transport $[5,19]$, physical activity [17], and other related environmental [15] (e.g., air emissions) or social sustainability phenomena (e.g., social inequalities/diversity) [20-22] have also been investigated. For example, Koohsari et al. [23], proposed a non-data-intensive and unconventional Space Syntax Walkability (SSW) framework that connects urban form (e.g., angular integration [24]) and urban function (e.g., population density) with increased walking for transport $(\mathrm{r}=0.76)$ [18]. However, Dovey and Pafka [14] criticized these aggregated and morphological walkability approaches, since they utilize factors such as density, functional mix, and access to networks (urban DMA). These factors are problematic to define or measure, and their synthesis in a single index can lead to a misspecified model of cities.

Nonetheless, in macro-scale walkability perspectives, the analytical details of urban design qualities and people's experience are totally excluded. In practice, macro-level walkability indicators cannot have a realistic and immediate impact on people's daily lives, because it is extremely difficult to alter the street layout of existing neighborhoods, or to increase activity density (jobs and housing), or to redesign the land-use patterns, or to develop more effective transit systems, in a short time frame. On this basis, a meta-analysis study [25] underlined the small impacts of macro-level environmental variables on making people drive less. For instance, Stevens [25] found that households' driving in areas with higher density tend to decrease by only $0.22 \%$.

Micro-level walkability audit tools, although they are less studied than macro-level instruments [1], typically require field or virtual systematic observations of several built and social environment factors that commonly are not incorporated into local GIS databases. These tools often include the assessment of easily modified urban design characteristics, for instance, the presence of sidewalks, sidewalk width, trees, lights, crossings, curb ramps, signals, benches, etc., as well as elements of local social conditions, such as graffiti, stray dogs, prostitution, drugs, litter, etc. [26, 27]. Particularly, Cain et al. [1] found that regardless of the macro-level walkability features, improvements in street design and crossing amenities, public transport stops, sidewalk quality, and aesthetics lead to higher physical activity levels for all age groups. Pikora et al. [3] showed that well-maintained footpaths are associated either with increased walking for transport or recreation near home, while a study of eight European cities found that lower levels of graffiti and litter contribute to higher physical activity levels [28]. Further, Kim et al. [29] revealed that pedestrians feel more comfortable when streets provide a comfortable width, trees, dedicated bus lanes, and zebra crossings. To that end, from a policy-making perspective, it is clear that microlevel walkability features require a short time frame for action with reasonable financing mechanisms and help city councils to improve the walking experience and increase pedestrian travel.

So far, several micro-level walkability audit tools, with different numbers of items and discrete management/training approaches, have been developed. Some of these have been designed for research purposes, but others have been proposed for community use and to raise awareness about active living environments [7]. Examples of validated micro-scale audit tools include the Systematic Pedestrian and Cycling Environmental Scan (SPACES) [3], the Irvine Minnesota Inventory (IMI) [10], the Pedestrian Environment Data Scan (PEDS) Tool [30], and the four versions (i.e., full, mini, abbreviated, and global) of the Microscale Audit of Pedestrian Streetscapes (MAPS) [31].

Interestingly, prior research on auditing tools has been mainly focused on four axes. First, to analyze statistically inter-rater reliability $[32,33]$; second, to assess the effectiveness of virtual audit tools in comparison to in-field auditing [34, 35]; third, to examine optimum sampling techniques $[9,36]$; and fourth, to validate their performance in quantifying effectively activity-friendly environments $[1,6]$. However, micro-level walkability auditing tools deal with several barriers that limit their power [34, 37]. They are laborintensive, time-consuming, present high costs for data collection and training $[7,9,36,37]$, and they depend on fickle circumstances like weather, security, and human fatigue.

Although evidence shows that virtual audits are equally reliable with comparison to in-situ observations [35], and the total time for virtual auditing is slightly less [38], the barriers (e.g., weather, security, fatigue etc.) and costs (e.g., funding, time, human resources, etc.) of virtual audits remain high, and large-scale data collection in larger areas remains a difficult effort. For example, Cain et al. [1] reported 28.5 minutes for the full version of the MAPS and its 120-item list, and Day et al. [10] highlighted 20 minutes of field work per segment for the IMI, which included a 162-item list. Badland et al. [38] compared the time required for a virtual and an in-situ audit tool of 51 items in a sample of 48 street segments $(158 \mathrm{~km})$. They found that the virtual observation method was quicker (115.3 minutes) compared to the physical audit (148.5 minutes), which required $22.3 \%$ more time to complete. However, Aghaabbasi et al. [37] reviewed the duration of eight in-field and virtual audits and found that in three of them the time was increased by $8 \%$ to $64 \%$. Slower virtual audits were explained by the presence of more complex street structures, the calculation of time to travel to the study area, or the number of auditing items. As a possible solution to labor intensive infield audits, Hanibuchi et al. [39] developed a crowdsourced online auditing method, with compensation of $\$ 5.00$ US for each participant, that required about 30 minutes to assess a 14 item checklist for three road segments. Moniruzzaman and Páez [9] suggested a model-based sample technique as a method of reducing the number of total street segments to be audited. However, their proposal demands active travel data and other independent indicators that limit the applicability to 
every city. On the other hand, a recent micro-level walkability approach from Europe avoided sampling strategies and opted to develop city centre wide street rating GIS inventories [21] by conducting massive virtual street observations from 15.736 segments in eight European city centers. Similarly, BartzokasTsiompras et al. [40] applied virtually an enhanced version of the MAPS-Mini audit tool [6] to assess 112.000 segments in about 21 months, requiring 46 trained observers.

Other walkability approaches use surveys to capture the perception of the walking environment and the neighborhood design. For example, the Neighborhood Environment Walkability Scale (NEWS) [41], measures the perceived local environment and it includes questions about aesthetics, pedestrian infrastructure, cleanliness, access to destinations and services, safety from crime or traffic, slope, parking spaces and more. Similarly, other authors have applied mixed walkability methods using objectively measured GIS-based and street auditing data. For instance, Moura et al. [42] presented a weighted walkability index for Lisbon, using 17 indicators and seven thematic dimensions: i.e., connectivity, convenience, comfort, conviviality, conspicuousness, coexistence, and commitment.

Therefore, this paper aims to:

- investigate whether a global and flexible multiple regression modeling approach can facilitate the estimation of average micro-level pedestrian attractiveness scores from open-access urban form- and function-related data; and

- apply a virtual audit tool that quantifies and maps at the segment-level microscale walkability scores in the city center of Athens, Greece.

\section{STUDY AREA}

This research was implemented in the city center of Athens, Greece (7.82 sq. km), and in particular included the wide area of the ongoing special urban development plan for Athens' historic center, as well as the first administrative district of Athens Municipality. In total, 23 administrative neighborhoods are included (see Figure 1).

The city centre of Athens presents a mix of urban problems, such as traffic congestion, limited sidewalk accessibility, illegal parking, air pollution, illegal drugs, homelessness, public space vandalism, as well as complex crises related to migration, and housing affordability issues. About 72,808 people reside within the study area [43], which is a magnet for the commercial, administrative, economic, and touristic activities of the whole metropolitan area.

Recently, the new local government listed walkability issues as a top priority in urban policy making, and decided to invest about 24 million euros in pedestrian infrastructure improvements (e.g., sidewalk re-engineering, public space redevelopments, enhanced lighting, etc.). Additionally, an emblematic urban redevelopment project, titled the "Grand Walk" (http://megalosperipatos.cityofathens.gr/, Accessed 29/09/2020), aims to redesign $6.3 \mathrm{~km}$ of primary streets and to release 50,000 sq. $\mathrm{m}$ of public space within the city centre.

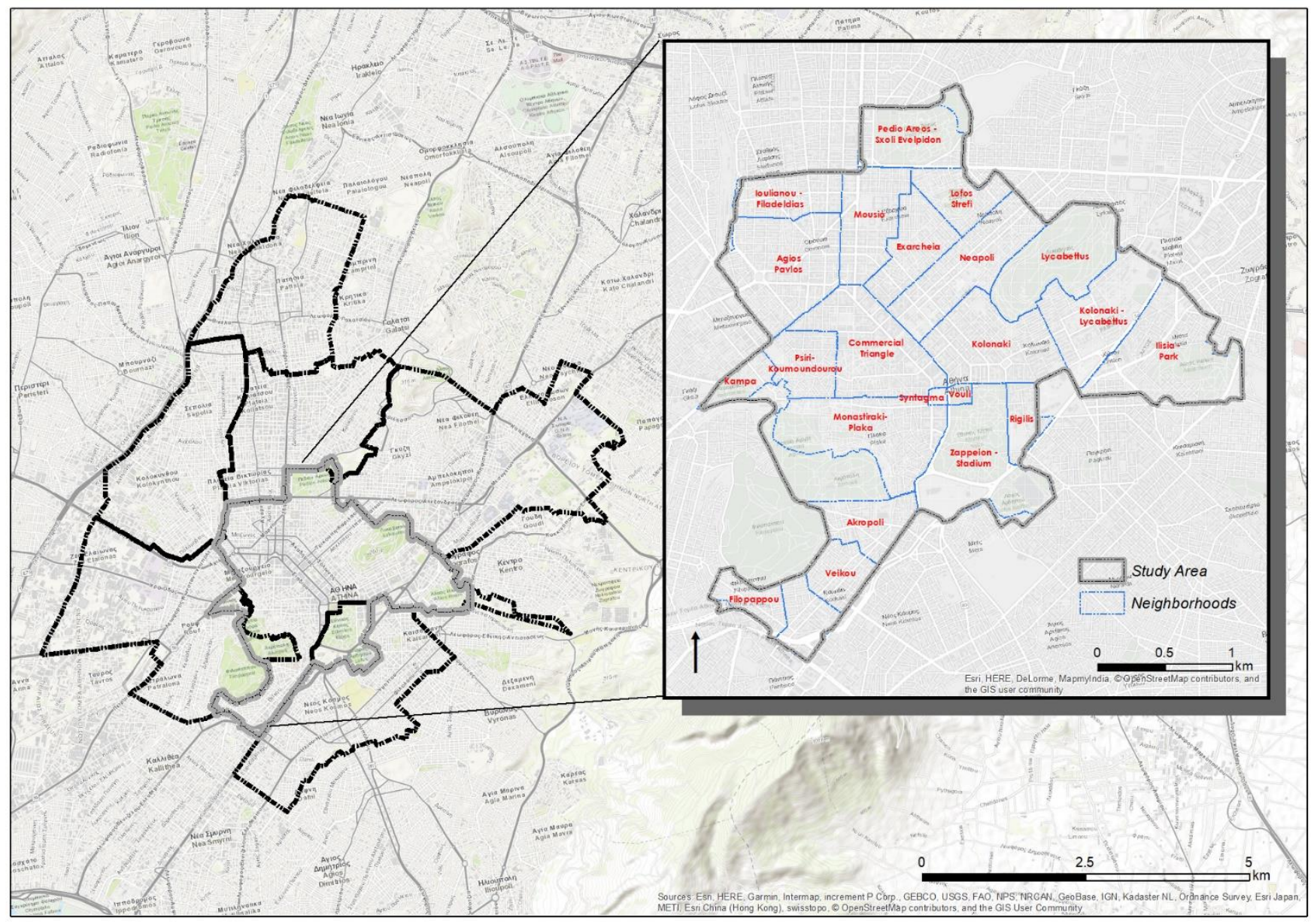

Figure 1. Boundaries of Athens municipal districts (left), and the neighborhoods of the city center area (right) 


\section{MATERIALS AND METHODS}

In this section we present the data, variables and their sources, as well as the methodological approach of the study. In Figure 2. the research flow is presented. Briefly, we applied a virtual walkability audit tool to collect street observation data for each street- and crossing-segment in Athens city centre and this process helped us to construct a microscale walkability index. The results of this work are a walking quality map and a set of aggregated indicators about 17 urban design topics. Followingly the research includes the development of multiple regression (OLS) model aiming to estimate the average scores of the walkability index (dependent variable) based on six open-access and macro-level correlates of walking (independent variables). In this manner, researchers and planners, working in strategic urban and transport planning, can save time and costs in collecting numerous street-level observation data.

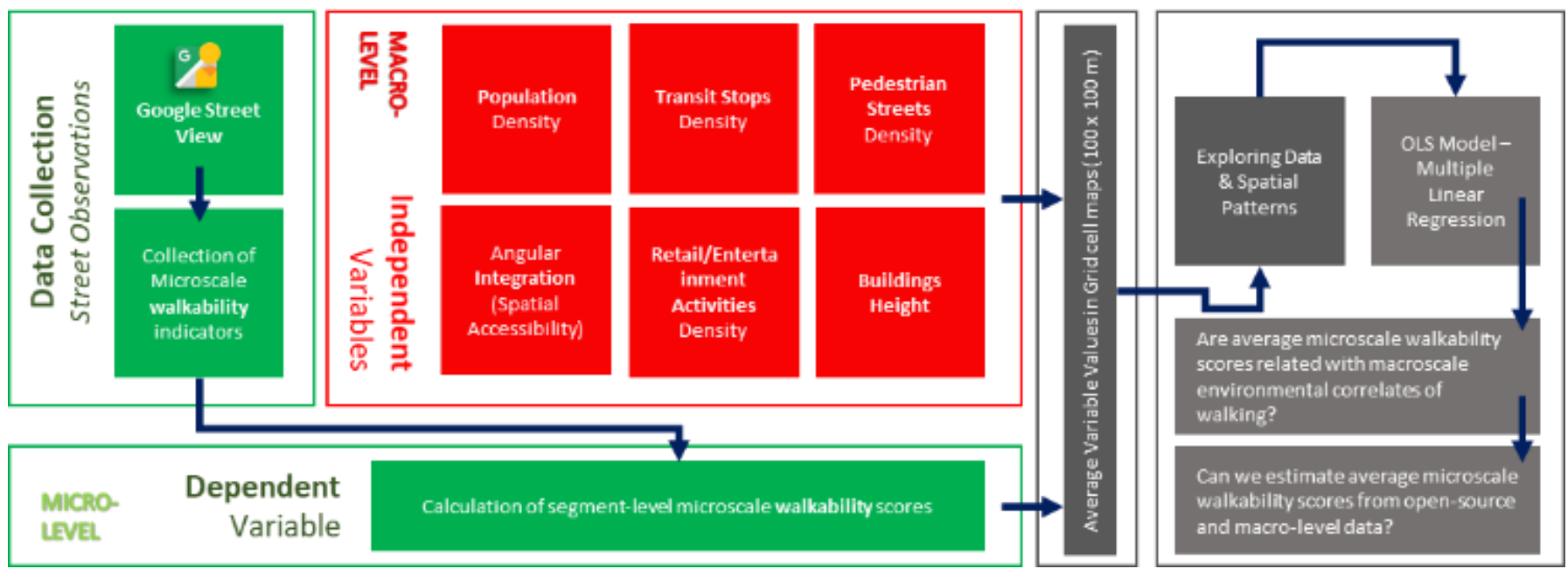

Figure 2. Research flow

\subsection{Dependent variable: Microscale walkability scores}

This research capitalizes on previous work carried out with the brief version of the Microscale Audit of Pedestrian Streetscapes (MAPS-mini) [6]. Evidence shows that this tool is highly and positively associated with increased physical activity, and has been recommended for use by planning practitioners [6]. Particularly, we used the online Google Street View (GSV) service and developed a virtual street rating process. Earlier research has indicated that virtual audit tools are equally reliable when compared to in-person field street rating processes $[21,35,44]$. Hence, we trained two observers for two days, both of whom were $\mathrm{PhD}$ students. Both recorded on a GIS database their street observations of a 17-item list related to environmental correlates of walking. According to the observer's responses, some items received zero or one point, while others earned up to two points [40]. In particular, each recording on the database involved separate observations of each side of each street, block by block, as well as of each crossing on both sides of the street. The street auditing process required about two months (May - June 2020) and the final GIS database contains street observations of 4.905 segments $(324 \mathrm{~km})$ and seventeen urban design topics. Briefly, the 17-item list of the micro-level walkability audit tool are the following: 1) commercial or/and entertainment buildings, 2) Parks or Plazas, 3) Transit stop(s), 4) Public siting, 5) Street lighting, 6) Building maintenance, 7) Absence of Graffiti, 8) Cycle lane, 9) Sidewalk presence, 10) Sidewalk maintenance, 11) Sidewalk buffers, 12) Tree shading provision, 13) Sidewalk width, 14) Traffic lanes, 15) Crossing with pedestrian walk signal, 16) Crossing with curb ramp(s), and 17) Crossing with marked crosswalk. More details about the virtual walkability audit tool and the scores per item can be found in a data article [40] published by Data in Brief Journal. Next, micro-scale walkability scores were computed both per street segment separately, and block-by-block, using the ratio of the sum of the collected points in the 17-item list to the maximum points for which a segment was eligible, to wit, 24 points. Scores closer to 1 indicated a highly organized built environment that is more walking-friendly, and on the other hand, scores near zero demonstrated a problematic and underdeveloped pedestrian streetscape. Subsequently, using the outcomes at street segment level, we aggregated the results using the Kernel Density Estimation to produce $100 \mathrm{~m}$ by 100 $\mathrm{m}$ grid cells with average segment density values weighted by micro-level walkability scores. Similar and comparable results are also available online for other fifty-eight European central urban areas [40].

\subsection{Exploratory variables}

The following six variables were selected as predictors of the micro-level walkability scores. All have been identified in previous studies as correlates of increased walking for transport or physical activity, while others have been included as parameters in macro-scale walkability indices.

\subsubsection{Spatial accessibility: Angular integration}

Integration is a key space syntax indicator and it quantifies how close the origin is to all other destinations. Higher integration values translate to a more connected network and improved physical activity behaviors [18], while lower integration means that the network is segregated [24]. Recently, a Canadian study found that a 1-unit increase in street integration is related to 0.22 min more transportation walking during a usual week [45]. Also, street integration is considered an alternative measure to intersections density [23], which is a standard parameter for street connectivity in macro-scale walkability indices. In this paper, we used the official roads polylines dataset provided by the Hellenic 
Statistical Authority (ELSTAT). The street line data was preprocessed for topological errors. Next, using QGIS v.2.16.3 software, we utilized the open source Space Syntax Toolkit plugin (v. 0.2.1) to calculate the angular integration values $(417 \mathrm{~m})$. Streets beyond the study area boundary and within the selected radius were retained in the analysis to avoid the edge-effect problem Similar to the method for calculating micro-level walkability scores, average integration values were computed at the $100 \mathrm{~m}$ by $100 \mathrm{~m}$ grid cell level using the Kernel Density Estimation.

\subsubsection{Population density}

Population density is a standard ingredient in several macrolevel walkability approaches $[5,17,22]$. Higher densities allow humans to live closer together, and in turn, the walking distances between people and local amenities are significantly shortened [14]. Hence, walking activity is significantly facilitated when people create dense urban communities. To estimate this variable, in our study we utilized the official census data of 2011 [43], which includes population statistics at the building-block level. To homogenize this data with the other variables of our research, we used the Kernel Density Estimation and produced average population density values per square kilometer in a $100 \mathrm{~m}$ by $100 \mathrm{~m}$ grid.

\subsubsection{Public transit stops density}

Public transit facilities provide alternative and sustainable mobility choices, and transit stop density is considered an important driver of higher pedestrian activity [46]. Particularly, a meta-analysis study [47] indicated that, by increasing the public transit options of a given neighborhood, walking activity is increased by about 30 minutes per week. For this variable, we utilized the official General Transit Feed Specification (GTFS) dataset of Athens Public Transport Organization (https://geodata.gov.gr/, Accessed 28/11/2020). The GTFS dataset, also known as Google Transit, includes several text files with timetable, route, and location data of the entire public transit system in a given area. Thus, in Athens, we used the latest stop location data (2017) and the Kernel Density Estimator to produce the average public transit stop density values per square kilometer at the $100 \mathrm{~m}$ by $100 \mathrm{~m}$ grid level.

\subsubsection{Pedestrian streets density}

Pedestrianization and car-free schemes are critical components in strengthening the walkability characteristics of a street, as they effectively improve the quality of public space, environmental comfort, and street vitality [11]. Thus, to calculate this variable, we fetched the pedestrianized pathways data from the overpassturbo.com API. In particular, we used the OSM tag "highway=pedestrian" and in turn, aided by the Kernel Density Estimation, we computed average pedestrian street length values per square kilometer at the $100 \mathrm{~m}$ by 100 $\mathrm{m}$ grid.

\subsubsection{Retail and entertainment activities}

Proximity to local retail shops and entertainment destinations (e.g., cafes, restaurants, bars, etc.) plays a key role in increased pedestrian activity and higher levels of transportrelated walking [48]. Therefore, higher densities of these destinations can create more pedestrian-friendly and attractive neighborhoods as they offer more proximate choices for shopping and leisure activities. Thus, for this variable we combined retail and entertainment related locations from openstreetmap.org (e.g., bars, cafes, grocery stores, restaurants, etc.). Particularly, we downloaded point data from the overpassturbo.com API using the following OSM tags: "shops=* OR amenity=bar OR amenity=restaurant $O R$ amenity=fast_food OR amenity=café". Next, we used the Kernel Density Estimation to calculate average density values of retail/entertainment locations per square kilometer at the $100 \mathrm{~m}$ by $100 \mathrm{~m}$ grid level.

\subsubsection{Building height}

Higher buildings constitute a strong predictor of higher pedestrian activity [46]. A recent study in New York City demonstrated that higher building density is one of the most consistent drivers of pedestrian traffic, since it creates more concentrated environments for employment, and provides access to multi-use spaces [46]. In this study, we used building height open data from a $10 \mathrm{~m}$ high resolution raster image provided by the European Environmental Agency (EEA) and the Copernicus Programme (Urban Atlas). These data include height information computed by remote sensing processing on IRS-P5 stereo images and other datasets, such as the digital surface model, the digital terrain model, and the normalized digital surface model (https://land.copernicus.eu/local/urbanatlas/building-height-2012, accessed: 22/09/20). Thus, as with our method for previous indicators, we computed average building height values at the $100 \mathrm{~m}$ by $100 \mathrm{~m}$ grid using ArcGIS for Desktop v.10.3 (ESRI, Redland, CA).

\subsection{Spatial analysis}

All data variables were tested for global and local spatial autocorrelation. The global spatial statistic pertained to the Global Moran's I index, which is an inferential statistical measure [21] that calculates the similarity of neighboring regions and helps with analyzing spatial patterns in the data. Thus, positive values of Moran's I, with high and statistically significant $\mathrm{z}$-scores, denote a clustered spatial pattern, while negative Moran's I and statistically significant z-scores depict a dispersed pattern tendency. Statistically significant z-scores and Moran's I values near to zero indicate a random spatial distribution.

Next, bivariate local spatial autocorrelation analysis [49] was performed to identify the spatial cross-correlation of micro-level walkability scores in relation to other, selected variables. Local Indicators of Spatial Association (LISA) is an appropriate method to map the spatial clusters or outliers in a region, as it can highlight smaller clusters that global statistics cannot reveal. An example of bivariate local Moran's I analysis map interpretation of microscale walkability scores and some socio-economic indicators may be seen in Bartzokas-Tsiompras et al. [21]. Our global and local spatial autocorrelation tests were carried out on GeoDa 1.12.1.161, and the spatial weights matrix was based on Queen contiguity, with the order set at two [50].

\subsection{Statistical analysis}

Multiple linear regression models [51] are widely known for their application in numerous research fields, including economics, demography, transportation, health, environmental sciences, etc. The concept of this statistical technique is quite simple. It enables analysts to establish the association between or among the tested variables along a straight line. It uses two or more explanatory variables and 
determines which of them are statistically important predictors of a given dependent variable. However, the data in independent variables should not show multicollinearity, and the Variance Inflation Factor (VIF) method should be applied and checked when values are lower than 7.5 [51].

Thus, multiple linear regression allows researchers to achieve a better understanding of the variation of the model, and the significance of each exploratory variable in the total variance. In this study, we apply the well-known Ordinary Least Squares (OLS) regression method [51] that aims to minimize the sum of square differences between the observed and predicted values. Specifically, this OLS linear regression model is expressed as:

$$
y_{i}=\beta_{o}+\beta_{1} x_{1}+\beta_{2} x_{2}+\cdots+\beta_{p} x_{i p}+\varepsilon
$$

where, for $\boldsymbol{i}=$ n observations: yi is the dependent variable, xi is the independent variables, $\beta \mathrm{o}$ is the $y$-intercept, $\beta p$ is the slope coefficient for each independent variable, and $\varepsilon$ is the residuals. The Adjusted R2 (0-1) is a statistical metric, and a critical diagnostic outcome of the regression model, that tells us how much variation of the data can be explained by the exploratory variables. Adjusted $\mathrm{R}^{2}$ values near to 1 demonstrate that the results are easily predictable, with insignificant error from the selected exploratory variables. For further details on multiple regression modeling, review
Chatterjee and Hadi [51].

\section{RESULTS}

\subsection{Descriptive statistics}

First, the street level angular integration values and the micro-level walkability scores are depicted in maps of Figure 5 and Figure 3, respectively. However, the average values of each indicator are illustrated in grid cells of $100 \mathrm{~m}$ by $100 \mathrm{~m}$ and can be seen in Figure 5. The total number of grid cells was $\mathrm{n}=782$ and the descriptive statistics for each variable are presented in Table 1 . The average walkability score per grid cell was low, at about $16.14 \%$; however, the raw scores by street segment ranged between $0 \%$ and $91.2 \%$. Regarding the street angular integration measure (see Figure 5), the mean value per grid cell was 2.209. The study area presented, on average, a high population density of approximately 10.412 people per square kilometer, while the public transport facilities were also dense, with 32.85 stops per square kilometer. Furthermore, the central Athens area showed a high pedestrian streets density, specifically, $3.31 \mathrm{~km}$ per square kilometer. Retail shops and entertainment activities demonstrated 5.25 facilities per square kilometer, and the average building height of $6.97 \mathrm{~m}$ was quite low, although the maximum value was $26.62 \mathrm{~m}$.

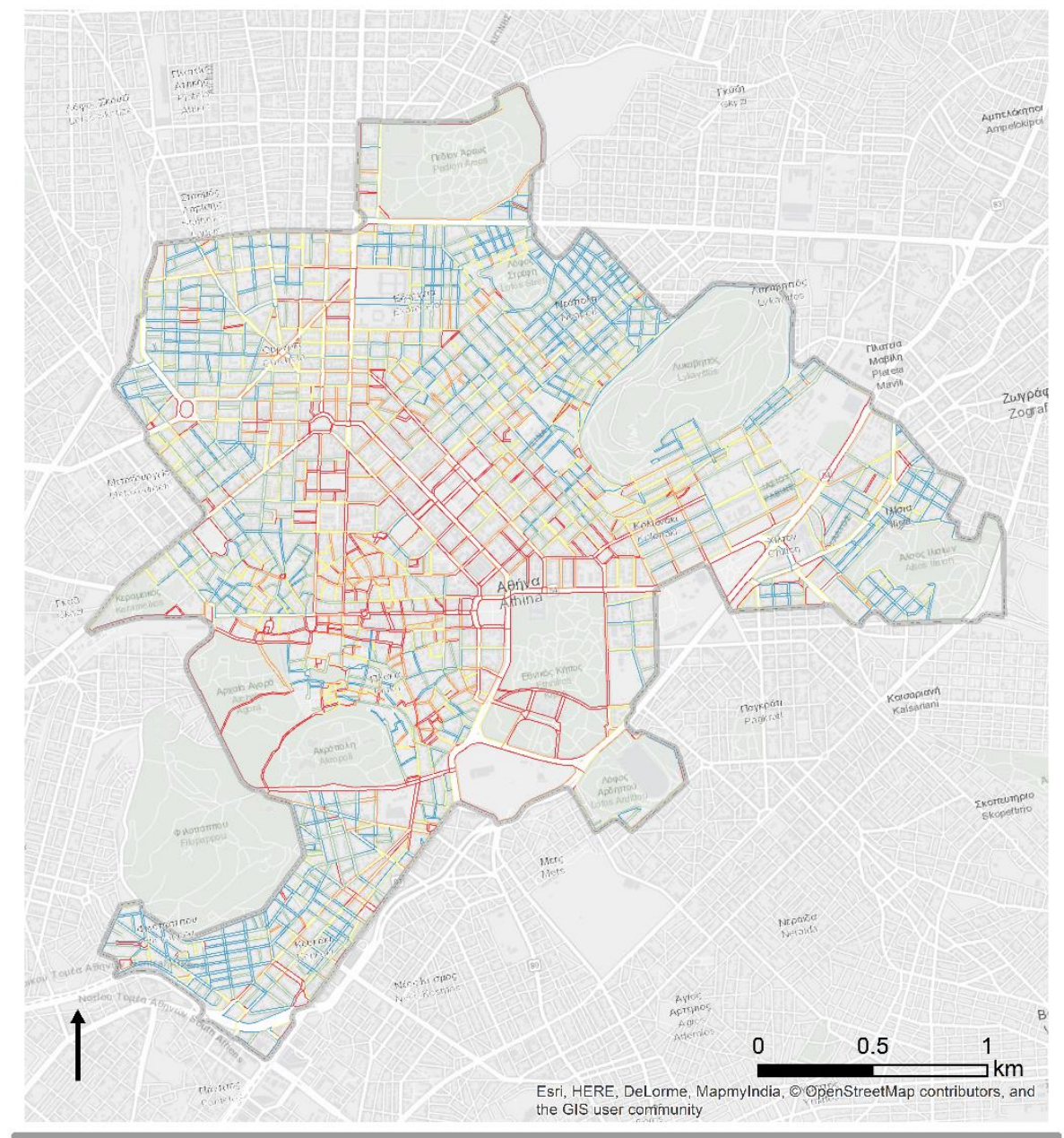

Microscale Walkability Scores

Figure 3. Quintile map of microscale walkability scores per street segment in Athens city center area 
Table 1. Descriptive statistics of the selected variables

\begin{tabular}{ccccc}
\hline $\mathbf{n = 7 8 2}$ (grid cells) & Min & Max & Mean & SD \\
\hline $\begin{array}{c}\text { Microscale } \\
\text { Walkability }\end{array}$ & 0.01 & 38.43 & 16.14 & 8.15 \\
$\quad \begin{array}{c}\text { Angular } \\
\text { Integration }\end{array}$ & 17.51 & 5907.92 & 2209.62 & 1228.47 \\
$\begin{array}{c}\text { Population } \\
\text { Density }\end{array}$ & 1811.01 & 25467.17 & 10411.87 & 5485.84 \\
$\begin{array}{c}\text { Transit Stops } \\
\quad \text { Density }\end{array}$ & 2.11 & 73.25 & 32.85 & 14.68 \\
$\begin{array}{c}\text { Pedestrian Streets } \\
\quad \text { Density }\end{array}$ & 0 & 15.74 & 3.32 & 2.97 \\
$\quad \begin{array}{l}\text { Retail/ } \\
\text { Entertainment }\end{array}$ & 0 & 8.62 & 5.25 & 1.62 \\
$\begin{array}{c}\text { Activities Density } \\
\text { Building Height }\end{array}$ & 0 & 26.62 & 6.97 & 5.58 \\
\hline
\end{tabular}

\subsection{Microscale walkability scores results}

In total, 4.905 street or crossing segments have been rated in a 17 -item checklist, and $76 \%$ and $21 \%$ of the audited GSV

images captured in 2019 and 2014, respectively. In 1.7\% of the total segments, due to limited or problematic GSV panoramic images, no data values were assigned. The creation of the virtual street-ratings GIS inventory took about 30 days. Samples of street ratings were cross-checked on an approximately daily basis by an experienced researcher, in order to validate the virtual auditors' application of the audit item guidelines during the data entry process.

Segment-level microscale walkability scores are shown in Figure 3, while the aggregated results of the walkability audit tool for Athens city centre are presented in Figure 4.
The percentages shown in bar charts of Figure 4 are weighted by the total length of segments per item rating (zero, one, or two points). The most important findings from these results are as follows. The majority of segments had a noncommercial or non-entertainment orientation, while the presence of parks and plazas, transit stops, and public seats (e.g., benches) were observed in less than approximately $12 \%$ of street segments. Street lighting conditions were problematic in about $2 \%$ of segments, while $17.68 \%$ present regularly installed lights on both sides of the street. More than half of street segments presented poorly maintained buildings $(61.54 \%)$ and sidewalks $(58.17 \%)$, there were facades vandalized with graffiti $(71.65 \%)$, and almost none of the audited streets possessed a bike lane. Interestingly, about $4 \%$ of segments did not have a paved walkway, while $45.03 \%$ had regularly installed buffers to separate sidewalks from traffic or to prevent illegal parking. A high share of street segments, over 55\%, were shaded by trees, or had stoas in more than $26 \%$ of their length. However, about $66 \%$ of the sidewalks were extremely narrow, measuring less than $2 \mathrm{~m}$ in width, while the majority of the segments $(68.52 \%)$ had a low-speed traffic character, since they were adjacent to a one-way road or included in a pedestrianized street. The conditions in pedestrian crossings were extremely poor, with pedestrianmarked crosswalks found in only $14 \%$ of the total crossings. More than half of evaluated crossings (51.28\%) were inaccessible to people with limited mobility as they lack curb ramps. Last but not least, $21.49 \%$ of the crossings had a pedestrian walk signal, which means that many intersections presented traffic safety concerns, since although a traffic light was present, a marked crosswalk was missing.

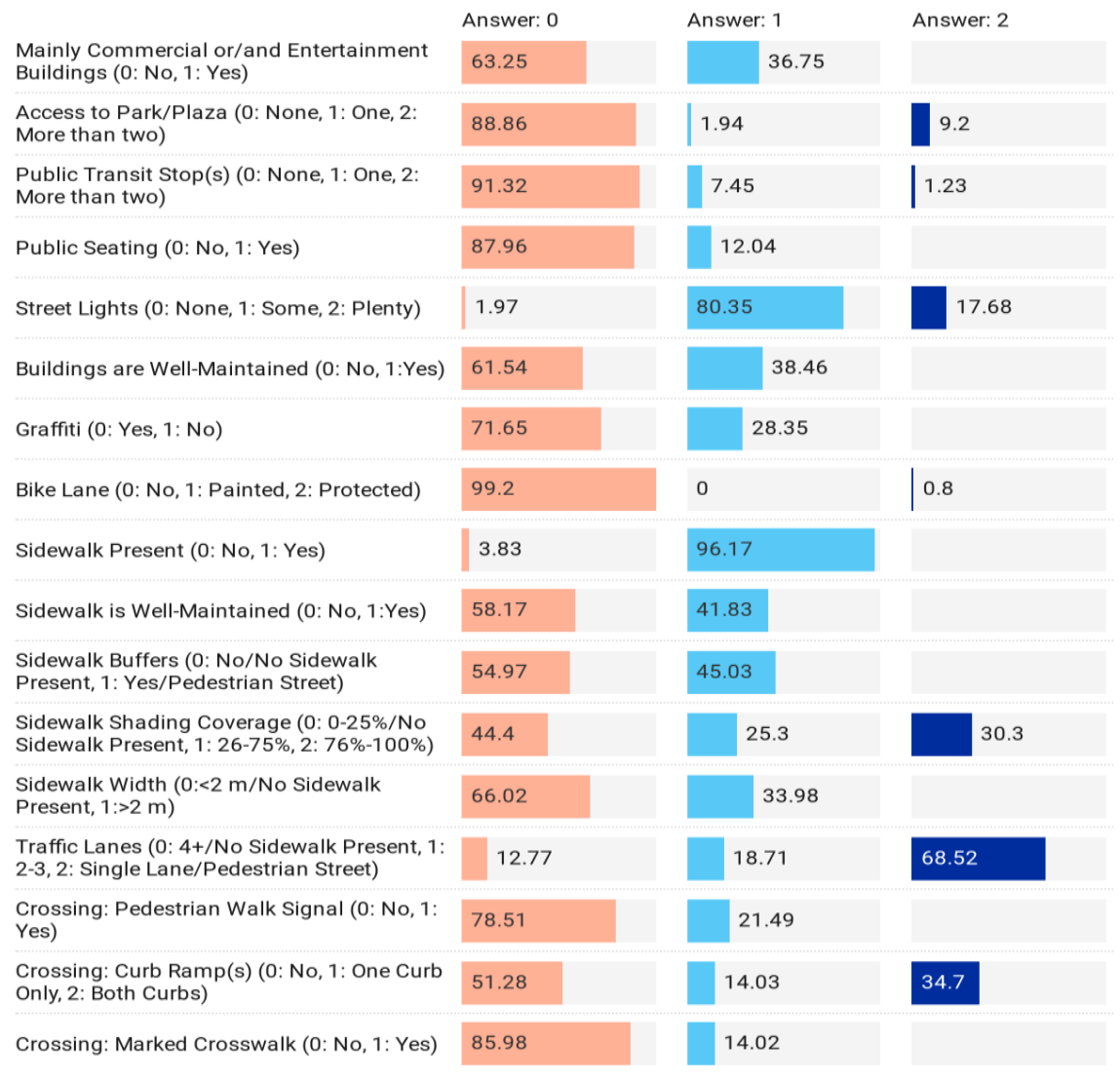

Figure 4. Aggregated results per audit tool item \& subscale 

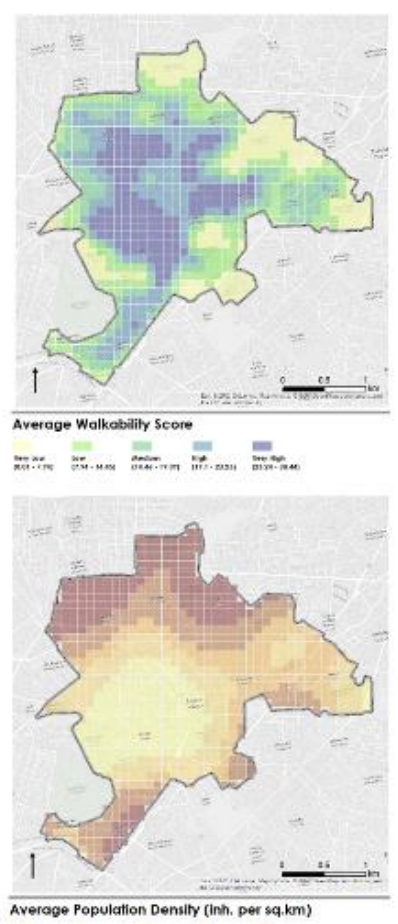

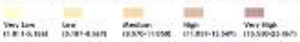

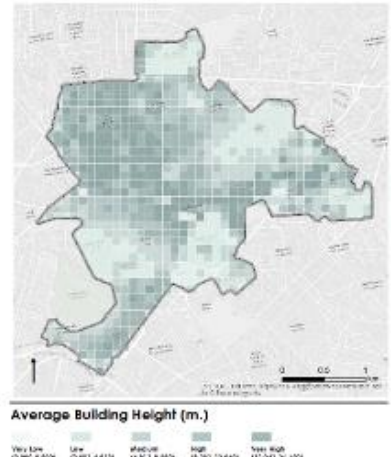

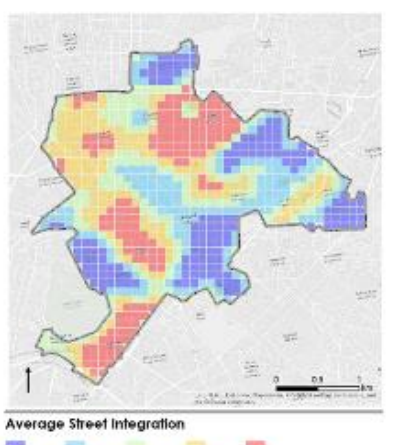

Nvercage Streat intogratilion $=$
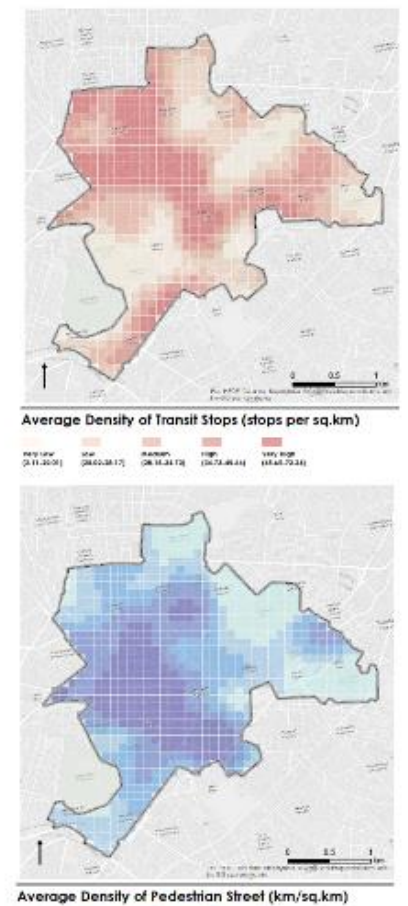

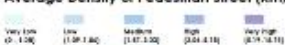
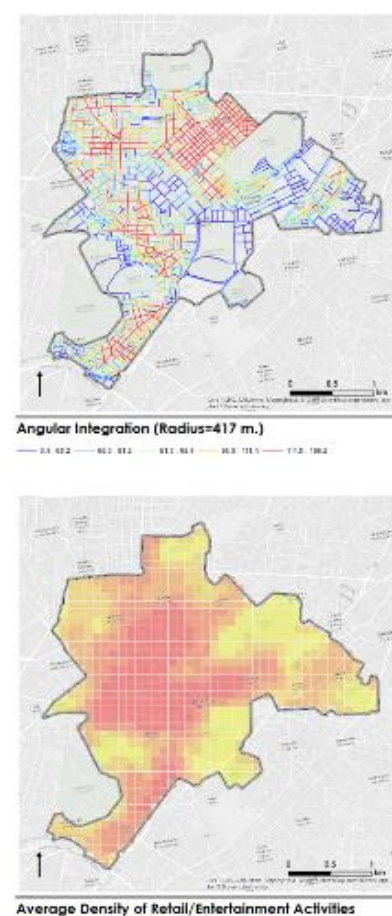

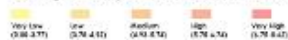

Figure 5. Quantile maps of the analyzed variables

In Figure 5, the average walkability scores of the audit tool are illustrated in $100 \mathrm{~m}$ by $100 \mathrm{~m}$ grid cells. The commercial triangle area (Omonia-Syntagma-Monastiraki), as well as the entertainment district of Psiri and the higher-income neighborhood of Kolonaki, exhibited the highest average walkability scores, while neighborhoods at the periphery of the central urban area (e.g., Filopappou, Kampa, Neapoli, Lofos Strefi, Ioulianou-Filadelfias, Ilisia-Park) showcased significantly more problematic characteristics in their pedestrian infrastructure and environment, that is, sidewalks and buildings were poorly maintained, sidewalks were also narrow, curbs ramp were lacking, and the land-use environment was mainly residential. At the street-segment level, the popular Dionisiou Aeropagitou Street, Plateia Monastirakiou Street, and the luxury retail and pedestrian street of Voukourestiou scored the highest average walkability values, with more than 0.77 points.

\subsection{Correlation analysis}

Pearson's correlation is a measure of the strength and direction of the relationship existing among two variables and the results are presented in Table 2. Firstly, the walkability index is strongly and positively correlated with the retail/entertainment density $(\mathrm{r}=0.83, \mathrm{p}<0.01)$, and it is moderately correlated with pedestrian streets $(\mathrm{r}=0.59,<0.01)$ and angular integration $(\mathrm{r}=0.64, \mathrm{p}<0.01)$. Population density is negatively correlated with the presence of pedestrian zones $(\mathrm{r}=-0.59, \mathrm{p}<0.01)$, while retail and entertainment activities density is positively related to pedestrian streets $(r=0.53$, $\mathrm{p}<0.01)$ and angular integration $(\mathrm{r}=0.55, \mathrm{p}<0.01)$. Finally, the building height is moderately correlated with transit density $(\mathrm{p}=0.63, \mathrm{p}<0.01)$ and retail and entertainment activities $(\mathrm{r}=0.58, \mathrm{p}<0.01)$.

Table 2. Pearson (r) correlation coefficients

\begin{tabular}{ccccccc}
\hline & WAL & POP & PED & INT & TRA & R\&E \\
\hline POP & $-0.28^{*}$ & 1 & & & & \\
PED & $0.59^{*}$ & $-0.59^{*}$ & 1 & & & \\
INT & $0.64^{*}$ & $0.32^{*}$ & $0.20^{*}$ & 1 & & \\
TRA & $0.35^{*}$ & $0.12^{*}$ & 0.04 & $0.17^{*}$ & 1 & \\
R\&E & $0.83^{*}$ & $-0.26^{*}$ & $0.53^{*}$ & $0.55^{*}$ & $0.46^{*}$ & 1 \\
BUH & $0.55^{*}$ & 0.03 & $0.17^{*}$ & $0.37^{*}$ & $0.63^{*}$ & $0.58^{*}$ \\
\hline
\end{tabular}

(*) $p$-value $<0.01$

Variable Codes: $($ WAL $)=$ Microscale Walkability, $(\mathrm{POP})=$ Population Density, $(\mathrm{PED})=$ Pedestrian Streets Density, $($ INT) $=$ Angular Integration, $($ TRA $)=$ Transit Stops Density, $(\mathrm{R} \& \mathrm{E})=$ Retail/Entertainment Activities Density, $(\mathrm{BUH})=$ Building Height. 


\subsection{Spatial autocorrelation analysis}

As can be seen in Table 3, all variables indicated a highly clustered spatial pattern, since all Global Moran's I values were far from zero, and z-score values were high and statistically significant $(\mathrm{p}<0.01)$. This allows as to effectively explore bivariate local cross-correlation patterns of microscale walkability scores with all other indicators. Table 4 summarizes the share of cells per cluster type per each combination of walkability and the other six variables, while Figure 6 illustrates the maps of Local Moran's I spatial autocorrelation results. Specifically, the spatial cluster and outlier types are interpreted as follows: 1) High-High (H-H) clusters, indicating that walkability is high and neighbors have also high values in the comparison variable, 2) High-Low (HL), showing a spatial outlier with high walkability scores among low values of the second indicator, 3) Low-Low (L-L) clusters, pertaining to areas where walkability is low and neighbors present also low values in the second variable, 4) Low-High (L-H) spatial outliers, describing areas where walkability is low and the neighbors have high values in the comparison variable, 5) Not significant, dealing with areas where values are equal to what is expected based on chance alone.

Table 3. Global Moran's I results

\begin{tabular}{cccc}
\hline Variable & I & \multicolumn{2}{c}{ Z-score } \\
\hline Microscale Walkability & 0.928 & 34.954 & $*$ \\
Angular integration & 0.926 & 34.898 & $*$ \\
Population density & 0.981 & 36.941 & $*$ \\
Public transit stops density & 0.945 & 35.608 & $*$ \\
Pedestrian streets density & 0.968 & 36.530 & $*$ \\
Retail/Entertainment activities density & 0.927 & 34.942 & $*$ \\
Building height & 0.718 & 27.071 & $*$ \\
\hline$(*)$ p-value $<0.01$ & & & \\
\hline
\end{tabular}

We found that Athens city centre demonstrated a significant level of population inequality in walkability spatial distribution, as we identified $25.45 \%$ of the area as a H-L spatial outlier. This situation relates to poor previous housing decisions, where planners have allowed commercial, tourism, administrative, and office buildings to dominate in the urban core. This finding is also consistent with Bartzokas-Tsiompras et al. [21], where the authors used Lorenz Curves and Gini coefficients to identify similarly striking spatial dissimilarities of microscale walkability scores in seven other European city centers.

Spatial accessibility is represented by local street integration, and this measure showed a uniform relationship with walkability scores. Almost same percentages were indicated per each cluster or outlier type. Interestingly, the area around Panepistimiou Street (see Figure 6) that hosts a major part of the ongoing "Grand Walk" redevelopment plan demonstrated higher walkability scores, but lower integration values, than the neighboring areas. This allows us to suggest street layout innervations (e.g., re-engineering a passages network) or the promotion of soft actions, such as the development of smart pedestrian wayfinding system solutions to boost place legibility and traversability.

Furthermore, consistent spatial associations were also identified between walkability and transit stops density. However, we located an H-L area of $13.3 \%$ that presents high walkability, yet lacks a range of public transportation choices with comparison to its nearby area. This pattern centers on the highly pedestrianized Monastiraki-Plaka touristic neighborhood, where adding transit options would be difficult. Thus, alternative solutions that connect the area with major nearby transportation hubs should be investigated (e.g., bike sharing stations).

Findings from the spatial cross-correlation of walkability and pedestrian streets density identified that a large part $(21.74 \%)$ of the car-free areas network (e.g., the commercial triangle) is associated with increased local walkability scores. To the contrary, $17.65 \%$ of the areas with low densities of pedestrianized streets tend to showcase lower walkability scores than their neighbors.

Also, the presence of shopping and entertainment activities presented a strong spatial interrelationship with walkability, as a high share of the total area (34.65\%) was classified both as a highly pedestrian-friendly area, and with an overwhelming shopping and entertainment character. About $27 \%$ of the grid cells showed that, when retail shops, bars, cafes, restaurants, etc. did not predominate in the district, then walkability scores were also low, which is a warning signal for planning indicating that street-level interventions are also required in more residential areas.

Last but not least, building height was also spatially correlated with walkability patterns. In about $28.64 \%$ of the areas, the higher the buildings, the higher the walkability was, while the opposite pattern appeared in $27.11 \%$ of the city centre. However, this was not the case in roughly $8.44 \%$ of the district, a finding that mainly applied in the touristic,historic, and highly pedestrianized neighborhood of MonastirakiPlaka, where numerous low-height buildings already exist and the environmental conditions for walking are usually well maintained.

Table 4. Share of total area per spatial cluster \& outlier (Local Moran's I) of walkability \& six macro-level design variables

\begin{tabular}{ccccccc}
\hline Walkability VS: & $\begin{array}{c}\text { Angular } \\
\text { integration }\end{array}$ & $\begin{array}{c}\text { Population } \\
\text { density }\end{array}$ & $\begin{array}{c}\text { Public transit } \\
\text { stops density }\end{array}$ & $\begin{array}{c}\text { Pedestrian } \\
\text { streets density }\end{array}$ & $\begin{array}{c}\text { Retail/ } \\
\text { Entertainment } \\
\text { activities density }\end{array}$ & $\begin{array}{c}\text { Building } \\
\text { height }\end{array}$ \\
\hline High-High Cluster & $30.82 \%$ & $17.65 \%$ & $23.79 \%$ & $21.74 \%$ & $34.65 \%$ & $28.64 \%$ \\
Low-Low Cluster & $30.18 \%$ & $15.09 \%$ & $24.55 \%$ & $29.16 \%$ & $26.85 \%$ & $4.11 \%$ \\
Low-High Outlier & $6.52 \%$ & $15.98 \%$ & $6.91 \%$ & $6.65 \%$ & $4.09 \%$ & $8.44 \%$ \\
High-Low Outlier & $6.14 \%$ & $25.45 \%$ & $13.30 \%$ & $17.65 \%$ & $32.99 \%$ & $31.20 \%$ \\
Not Significant & $26.34 \%$ & $25.83 \%$ & $31.46 \%$ & $24.81 \%$ & \\
\hline
\end{tabular}



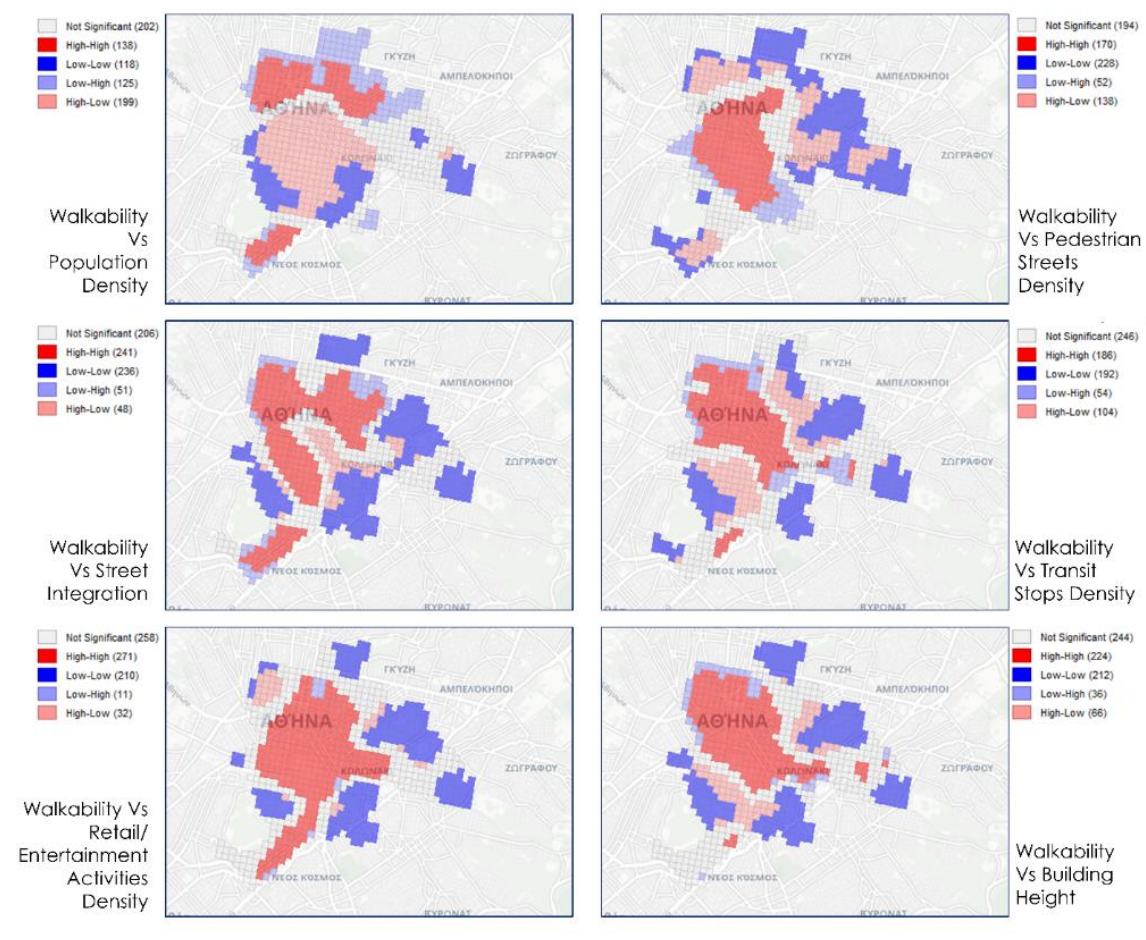

Figure 6. Bivariate Local Moran's I maps of walkability \& six related variables

\subsection{Multiple regression modeling}

The multiple linear regression model was applied to predict the calculated average microscale walkability scores. We found a significant regression equation $(F(6,775)=606$, $\mathrm{p}<0.01$ ) with an adjusted $\mathrm{R}^{2}$ of $82.3 \%$ (see Table 5).

Table 6 illustrates that the average estimated microscale walkability score is equal to $1.542+0.003 *$ (angular integration) $-0.0004 *($ inhabitants per sq.km) $+0.04 *$ (transit stops per sq.km) $+0.389 *(\mathrm{~km}$ of pedestrian zones per sq $\mathrm{km}$.) $+1.55^{*}$ (retail/entertainment activities per sq.km) $+0.198 *$ (meters on average building height per sq.km.). Thus, excepting population density, all five other variables had a statistically significant $(p<0.01)$ positive relationship with walkability. The negative, but weak, relationship of microscale walkability and population density is paradoxical, as in several macro-scale walkability studies the population density is considered a standard ingredient $[4,5,17,22]$ and a symbol of good urbanism [2]. Possibly, if activity densityjobs and population density - were included in the model, the outcome of this relationship would be quite the opposite.

Table 5. Overall diagnostics for the OLS model

\begin{tabular}{ccc}
\hline Adjusted R $^{2}$ & AICc & Joint F-Statistic \\
\hline 0.8229 & $\begin{array}{c}4.155 .62 \\
(*) p \text {-value }<0.01\end{array}$ & $775^{*}$ \\
\hline
\end{tabular}

Additionally, multiple regression modeling results suggested that retail and entertainment density was the strongest driver of walkability in central Athens $(\beta=1.546$, $\mathrm{p}<0.01)$. A one-point increase in shopping or entertainment activities average density (points per sq.km), with all other variables being constant, will sharply increase the average microscale walkability scores by $1.55 \%$. This finding is important, since it highlights the connection between shopping and leisure-time clusters in the city with past urban redevelopment policy targets that have, for tourism reasons, prioritized the popular streets of the city centre area over upgrading quality of life in more residential neighborhoods.

Table 6. Statistics of the OLS model (Dependent Variable = Microscale Walkability)

\begin{tabular}{ccccc}
\hline Variable** & Coefficient $(\boldsymbol{\beta})$ & Standard Error & t-statistic & VIF \\
\hline Intercept & $1.542686^{*}$ & 0.657317 & 2.3469 & ---- \\
Angular Integration & $0.003159^{*}$ & 0.000162 & 19.551 & 2.61 \\
Population Density & $-0.000420^{*}$ & 0.000037 & -11.295 & 2.76 \\
Transit Stops Density & $0.036500^{*}$ & 0.011858 & 3.0780 & 2.01 \\
Pedestrian Streets Density & $0.389594^{*}$ & 0.061229 & 6.3629 & 2.20 \\
$\quad$ Retail/ & $1.546943^{*}$ & 0.140953 & 10.974 & 3.45 \\
Entertainment & $0.198734^{*}$ & 0.031732 \\
Activities Density & $(*)$-value<0.01 \\
Building Height & 6.2629 & 2.08 \\
\hline \multicolumn{5}{c}{} \\
\hline \multicolumn{4}{c}{ All variables represent average values of grid cell maps $(100 \times 100 m)$} \\
\hline
\end{tabular}


The model also indicated that, the higher the average density of car-free areas $(\beta=0.389, \mathrm{p}<0.01)$ or the higher the average building height $(\beta=0.198, p<0.01)$, then the higher the level of pedestrian friendliness, as coefficient values of these variables were positive and statistically significant, respectively. This finding was expected, as centrally located pedestrianized areas of high quality place making have the power to boost overall micro-level walkability values, and in turn, urban sustainability and livability levels [11]. Positive and statistical significant relationships $(\mathrm{p}<0.01)$ were also found with transit stop density $(\beta=0.036, p<0.01)$ and street integration $(\beta=0.003, p<0.01)$. However, the strength of these associations was weak in comparison to shopping and entertainment activities density and pedestrian street density. This finding points out that these macro-level parameters of walkable urbanism that have the capacity to address cardependent lifestyles, such as better spatial accessibility and public transport availability, do not always result in pedestrian-friendly local areas possessing features of higher quality urban design.

\section{DISCUSSION}

In addition to mapping, and analyzing the walkability scores of a brief virtual streetscape audit tool, this study also initiated the exploration of the application of a multiple linear regression model to estimate average micro-level walkability values based on open datasets of macro-scale environmental factors. On this basis, this work contributes new evidences to the developing body of walkability methods research [12], and presents new insights from a European setting about the relationships between micro-level streetscape features and macro-level built environment attributes. Freely available high spatial resolution geospatial data (e.g., openstreetmap.com, EEA, population census) describing fundamental elements of urban form and function supported our efforts to prepare the statistical model for research. We used six exploratory variables that have been underlined elsewhere as strong pillars in increasing active travel and non-motorized trips. Namely, these were: average values of local angular integration [19]; population density[4]; transit stops density [46, 47]; retail or entertainment activities density [48]; pedestrian streets density [11]; and mean building height [46].

The multiple linear regression model helped us develop a better understanding of the variables that were strong predictors of micro-level walkability scores, and explained about $82.3 \%$ of the total variation. Our findings also suggested that microscale walkability scores are highly influenced by the density of retail and entertainment activities. Thus, for onepoint increase in the average density representing these activities, keeping the other variables constant, we would expect to see an approximate $1.55 \%$ increase in average microscale walkability scores. Others have also shown that active uses are important predictors of pedestrian activity, and thus commercial or touristic streets, having active frontages, are a suitable indicator to prioritize streetscape improvements in the city [8]. Additionally, this result is in line with the decision of some walkability audit tool developers to mix the items by combining micro-level streetscape characteristics with macro-scale features of the built environment, such as land-use patterns $[1,6,10]$.

We identified pedestrian streets average density as the second most influential predictor of average micro-level walkability values $(\beta=0.389, \quad \mathrm{p}<0.01)$. This finding demonstrates the power of car-free schemes to upgrade the quality of living more widely [1]. However, this result was expected, as pedestrian areas often stand out due to their higher quality design, where people are more protected and feel more comfortable walking.

High-rise buildings are one aspect of compact urban development, since they attract more jobs and population, and are usually surrounded by well-connected transit hubs and diverse land-use patterns. Our findings, though, enhance this argument with new evidence. We indicated that a high-rise urban development pattern $(\beta=0.198, \quad p<0.01)$ is also associated with higher levels of pedestrian-friendly streetscapes. However, empirical evidence from a New York City case study [46] found that higher building densities, and even the day of the week, are more influential than basic streetscape factors (e.g., sidewalk coverage, street amenities, pavement quality) in increasing pedestrian activity.

Transit stops and street integration are frequently referred to as vital parameters of walkable neighborhoods, since they provide alternative transportation choices in relation to carcommuting, and an interconnected street layout that facilitates walking travel behavior. Nonetheless, our study reported a weak but positive relationship both between transit density $(\beta=0.036, p<0.01)$, and street integration $(\beta=0.003, \mathrm{p}<0.01)$, with average micro-level walkability scores.

An interesting finding related to the spatial inequities of walkability and population. The regression model highlighted that population density $(\beta=-0.0004, p<0.01)$ is negatively associated with micro-level walkability values, but this association was weak. This finding is counterintuitive in terms of macro-level walkability measures, since housing or population intensity is considered a constant driver of walkable and compact urbanism $[2,4]$. On the other hand, this result is probably the effect of a highly touristic city center. Hence, this insight needs further research in a city-wide context in order to understand the differences of macro- or micro-level walkability approaches and their spatial relation to the demographic structure of the city, as well as the underlying drivers preventing more people from living in the urban core. Recently, other authors have warned against the neighborhood inequities created by the unequal spatial distribution of microscale walkability scores, and reported results from eight European city centers [21] and an urban region in China [20]. In terms of urban studies, this result is critical since it enhances the evidence in the literature regarding the possible negative implications of high-quality place-making strategies on population dynamics.

Similar trends with the regression model results also presented in local spatial autocorrelation analysis. We found that more than $29 \%$ of the total area with high walking quality has mainly retail or entertainment clusters, presents higher buildings, and offers greater spatial accessibility. Accordingly, in more than $27 \%$ of the total area, we found low walkability clusters with concurrent low street integration, low intensity of pedestrianized areas and retail or entertainment establishments, and lower-height buildings. To the contrary, in one out of four grid cells, the spatial inequity of high walkability and low population density is evident, and requires policy attention to put into practice better housing mechanisms.

Clearly pedestrian streetscapes in central Athens area have a lot of room for future improvements. Excepting the urban core, where the tourism and commercial magnets are located, 
almost all the peripheral districts presented highly problematic characteristics in their pedestrian environments and infrastructure. Particularly, the sidewalks and buildings were poorly maintained, sidewalks were narrow, curb ramps were lacking, crosswalks were missing, and graffiti was almost everywhere on public spaces and buildings. However, sidewalks were efficiently shaded, they were protected from traffic with buffers, and many roads were either pedestrian or residential. Also, public spaces such as parks or plazas were insufficient, and seating provisions were rare. All these issues require simple urban solutions that are cost-effective and can be developed in realistic time frames.

This methodological framework provided a geospatial solution to quantify and map micro- and macro-level relationships of different walkability measures and attributes. Thus, this exercise was beneficial to understanding that not all macro-scale built environment features result in a betterdesigned pedestrian environment, although they can effectively decrease car-dependent lifestyles [15]. This finding is vital in terms of quality of living, since it proves that urban planning applications are not, in practice, integrated either with urban design strategies, or inclusive urban mobility solutions.

While our method enhanced the literature in walkability measures, it possesses some limitations. First, the audit-based walkability scores at the edges of the study area suffer from the edge effect, as street segments beyond the city centre boundary have not been audited. Second, since this work utilizes aggregated data to grid cells, the modifiable areal unit problem (MAUP) might apply [52]. Third, Google Street View in some cases presents problematic panoramic images and thus limits the ability of auditors to provide reliable observations [34]. Forth, the residuals of the regression model have not been tested for spatial autocorrelation and normal distribution. Last but not least, we did not report a correlation of the walkability index with pedestrian counts or physical activity data, since data scarcity is still a barrier.

\section{CONCLUSION}

The presence of retail and entertainment activities as well as the presence of pedestrian zones have been identified as the strongest macro-level environmental correlates of more walking-friendly streets in Athens city centre. Additionally, the created OLS regression model provided the basis to estimate average microscale walkability scores using opensource environmental data. In this manner, planners and public health researchers can easily calculate average pedestrianfriendliness levels in other districts in Athens metro area, avoiding significant costs in collecting street observation data and prioritizing neighborhoods requiring street-level interventions.

Future research studies are encouraged to apply our concept in other European locations, using similar data [47], as well as to investigate the addition of further exploratory built or social environment variables (e.g., topography, multiple deprivation, air quality, etc.) and the employment of spatial regression models, such as Geographically Weighted Regression (GWR).

\section{ACKNOWLEDGMENT}

This research is co-financed by Greece and the European
Union through the program "Human Resources Development, Education and Lifelong Learning" in the context of the project "Strengthening Human Resources Research Potential via Doctorate Research" (MIS-5000432), implemented by the State Scholarships Foundation (IKY).

\section{REFERENCES}

[1] Cain, K.L., Millstein, R.A., Sallis, J.F., Conway, T.L., Gavand, K.A., Frank, L.D., Saelens, B.E., Geremia, C.M., Chapman, J., Adams, M.A., Glanz, K., King, A.C. (2014). Contribution of streetscape audits to explanation of physical activity in four age groups based on the microscale audit of pedestrian streetscapes (MAPS). Social Science \& Medicine, 116: 82-92. https://doi.org/10.1016/j.socscimed.2014.06.042

[2] Ewing, R., Cervero, R. (2010). Travel and the built environment: A meta-analysis. Journal of the American Planning Association, 76(3): 265-294. https://doi.org/10.1080/01944361003766766

[3] Pikora, T.J., Giles-Corti, B., Knuiman, M.W., Bull, F.C., Jamrozik, K., Donovan, R.J. (2006). Neighborhood environmental factors correlated with walking near home: Using SPACES. Medicine \& Science in Sports \& Exercise, 38(4): 708-714. https://doi.org/10.1249/01.mss.0000210189.64458.f3

[4] Frank, L.D., Schmid, T.L., Sallis, J.F., Chapman, J., Saelens, B.E. (2005). Linking objectively measured physical activity with objectively measured urban form. American Journal of Preventive Medicine, 28: 117-125. https://doi.org/10.1016/j.amepre.2004.11.001

[5] Grasser, G., van Dyck, D., Titze, S., Stronegger, W.J. (2016). A European perspective on GIS-based walkability and active modes of transport. The European Journal of Public Health, 27(1): 145-151. https://doi.org/10.1093/eurpub/ckw118

[6] Sallis, J.F., Cain, K.L., Conway, T.L., Gavand, K.A., Millstein, R.A., Geremia, C.M., Frank, L.D., Saelens, B.E., Glanz, K., King, A.C. (2015) Is Your Neighborhood Designed to Support Physical Activity? A Brief Streetscape Audit Tool. Preventing Chronic Disease, 12 : 150098. https://doi.org/10.5888/pcd12.150098

[7] Brownson, R.C., Hoehner, C.M., Day, K., Forsyth, A., Sallis, J.F. (2009). Measuring the built environment for physical activity. American Journal of Preventive Medicine, 36(4): S99-S123.e12. https://doi.org/10.1016/j.amepre.2009.01.005

[8] Park, K., Ewing, R., Sabouri, S., Larsen, J. (2019). Street life and the built environment in an auto-oriented US region. Cities, 88: 243-251. https://doi.org/10.1016/j.cities.2018.11.005

[9] Moniruzzaman, M., Páez, A. (2012). A Model-Based Approach to Select Case Sites for Walkability Audits. Health \& Place, 18(6): 1323-1334. https://doi.org/10.1016/j.healthplace.2012.09.013

[10] Day, K., Boarnet, M., Alfonzo, M., Forsyth, A. (2006). The Irvine-Minnesota inventory to measure built environments. American Journal of Preventive Medicine, 30(2): 144-152. https://doi.org/10.1016/j.amepre.2005.09.017

[11] Nieuwenhuijsen, M.J., Khreis, H. (2016). Car free cities: Pathway to healthy urban living. Environment 
International,

94:

$251-262$

https://doi.org/10.1016/j.envint.2016.05.032

[12] Wang, H., Yang, Y. (2019). Neighbourhood walkability: A review and bibliometric analysis. Cities, 93: 43-61. https://doi.org/10.1016/j.cities.2019.04.015

[13] Forsyth, A. (2015). What is a walkable place? The walkability debate in urban design. Urban Design International, 20:

274-292. https://doi.org/10.1057/udi.2015.22

[14] Dovey, K., Pafka, E. (2020). What is walkability? The urban DMA. Urban Studies, 57(1): 93-108. https://doi.org/10.1177/0042098018819727

[15] Frank, L.D., Sallis, J.F., Conway, T.L., Chapman, J.E., Saelens, B.E., Bachman, W. (2006). Many pathways from land use to health: Associations between neighborhood walkability and active transportation, body mass index, and air quality. Journal of the American Planning Association, 72(1): 75-87. https://doi.org/10.1080/01944360608976725

[16] Bartzokas-Tsiompras, A., Photis, Y.N. (2017). What matters when it comes to "Walk and the City"? Defining a weighted GIS-Based walkability index. Transportation Research Procedia, 24(1): 523-530. https://doi.org/10.1016/j.trpro.2017.06.001.

[17] Frank, L.D., Sallis, J.F., Saelens, B.E., Leary, L., Cain, K., Conway, T.L., Hess, P.M. (2010). The development of a walkability index: Application to the neighborhood quality of life study. British Journal of Sports Medicine, 44(13):

924-933. https://doi.org/10.1136/bjsm.2009.058701

[18] Koohsari, M.J., Owen, N., Cerin, E., Giles-Corti, B., Sugiyama, T. (2016). Walkability and walking for transport: Characterizing the built environment using space syntax. International Journal of Behavioral Nutrition and Physical Activity, 13: https://doi.org/10.1186/s12966-016-0448-9

[19] Koohsari, M.J., Owen, N., Cole, R., Mavoa, S., Oka, K., Hanibuchi, T., Sugiyama, T. (2017). Built environmental factors and adults' travel behaviors: Role of street layout and local destinations. Preventive Medicine, 96: 124-128. https://doi.org/10.1016/j.ypmed.2016.12.021

[20] Zhou, H., He, S., Cai, Y., Wang, M., Su, S. (2019). Social inequalities in neighborhood visual walkability: Using street view imagery and deep learning technologies to facilitate healthy city planning. Sustainable Cities and Society, 50: 101605. https://doi.org/10.1016/j.scs.2019.101605

[21] Bartzokas-Tsiompras, A., Tampouraki, E.M., Photis, Y.N. (2020). Is walkability equally distributed among downtowners? Evaluating the pedestrian streetscapes of eight European capitals using a micro-scale audit approach. International Journal of Transport Development and Integration, 4(1): 75-92. https://doi.org/10.2495/TDI-V4-N1-75-92

[22] Bartzokas-Tsiompras, A., Photis, Y.N. (2020). Does neighborhood walkability affect ethnic diversity in Berlin? Insights from a spatial modeling approach. European Journal of Geography, 11(1): 163-187. https://doi.org/10.48088/ejg.a.bar.11.1.163.187

[23] Koohsari, M.J., Oka, K., Owen, N., Sugiyama, T. (2019). Natural movement: A space syntax theory linking urban form and function with walking for transport. Health \& Place, 58: 102072 https://doi.org/10.1016/j.healthplace.2019.01.002
[24] Hillier, B., Penn, A., Hanson, J., Grajewski, T., Xu, J. (1993). Natural movement: Or, configuration and attraction in urban pedestrian movement. Environment and Planning B: Planning and Design, 20(1): 29-66. https://doi.org/10.1068/b200029

[25] Stevens, M.R. (2017). Does compact development make people drive less? Journal of the American Planning Association, $\quad$ Routledge, 83(1): 7-18. https://doi.org/10.1080/01944363.2016.1240044

[26] Millstein, R.A., Cain, K.L., Sallis, J.F., Conway, T.L., Geremia, C., Frank, L.D., Chapman, J., Van Dyck, D., Dipzinski, L.R., Kerr, J., Glanz, K., Saelens, B.E. (2013). Development, scoring, and reliability of the microscale audit of pedestrian streetscapes (MAPS). BMC Public Health, 13: 403. https://doi.org/10.1186/1471-2458-13403

[27] Bartzokas-Tsiompras, A., Paraskevopoulos, Y., Sfakaki, A., Photis, Y.N. (2021). Addressing street network accessibility inequities for wheelchair users in fifteen european city centers. In: Nathanail, E.G., Adamos, G. and Karakikes, I., (eds), Advances in Mobility-as-aService $\quad$ Systems, 1278: 1022-1031. https://doi.org/10.1007/978-3-030-61075-3_98

[28] Ellaway, A., Macintyre, S., Bonnefoy, X. (2005). Graffiti, greenery, and obesity in adults: Secondary analysis of European cross sectional survey. BMJ, British Medical Journal Publishing Group, 331: 611-612. https://doi.org/10.1136/bmj.38575.664549.F7

[29] Kim, S., Park, S., Lee, J.S. (2014). Meso- or micro-scale? Environmental factors influencing pedestrian satisfaction. Transportation Research Part D: Transport and Environment, 30 : 10-20. https://doi.org/10.1016/j.trd.2014.05.005

[30] Clifton, K.J., Livi Smith, A.D., Rodriguez, D. (2007). The Development and Testing of an Audit for the Pedestrian Environment. Landscape and Urban Planning, 80(1-2): 95-110. https://doi.org/10.1016/j.landurbplan.2006.06.008

[31] Sallis, J.F. Microscale Audit of Pedestrian Streetscapes (MAPS). https://drjimsallis.org/measure_maps.html, accessed on Jan. 4, 2021.

[32] Brownson, R.C., Hoehner, C.M., Brennan, L.K., Cook, R.A., Elliott, M.B., McMullen, K.M. (2004). Reliability of 2 instruments for auditing the environment for physical activity. Journal of Physical Activity and Health, Human Kinetics, Inc., 1(3): 191-208. https://doi.org/10.1123/jpah.1.3.191

[33] Boarnet, M.G., Day, K., Alfonzo, M., Forsyth, A., Oakes, M. (2006) The Irvine-Minnesota inventory to measure built environments. American Journal of Preventive Medicine, 30(2): 153-159.e43. https://doi.org/10.1016/j.amepre.2005.09.018

[34] Lee, S., Talen, E. (2014). Measuring walkability: A note on auditing methods. Journal of Urban Design, 19: 368388. https://doi.org/10.1080/13574809.2014.890040

[35] Phillips, C.B., Engelberg, J.K., Geremia, C.M., Zhu, W., Kurka, J.M., Cain, K.L., Sallis, J.F., Conway, T.L., Adams, M.A. (2017). Online versus In-Person Comparison of Microscale Audit of Pedestrian Streetscapes (MAPS) Assessments: Reliability of Alternate Methods. International Journal of Health Geographics, 16: 27. https://doi.org/10.1186/s12942017-0101-0 
[36] McMillan, T.E., Cubbin, C., Parmenter, B., Medina, A.V., Lee, R.E. (2010). Neighborhood sampling: How many streets must an auditor walk? International Journal of Behavioral Nutrition and Physical Activity, 7: 20. https://doi.org/10.1186/1479-5868-7-20

[37] Aghaabbasi, M., Moeinaddini, M., Shah, M.Z., AsadiShekari, Z. (2018). Addressing issues in the use of google tools for assessing pedestrian built environments. Journal of Transport Geography, 73: 185-198. https://doi.org/10.1016/j.jtrangeo.2018.10.004

[38] Badland, H.M., Opit, S., Witten, K., Kearns, R.A., Mavoa, S. (2010). Can virtual streetscape audits reliably replace physical streetscape audits? Journal of Urban Health, 87: 1007-1016. https://doi.org/10.1007/s11524010-9505-x

[39] Hanibuchi, T., Nakaya, T., Inoue, S. (2019). Virtual audits of streetscapes by crowdworkers. Health \& Place, 59:

102203.

https://doi.org/10.1016/j.healthplace.2019.102203

[40] Bartzokas-Tsiompras, A., Photis, Y.N., Tsagkis, P., Panagiotopoulos, G. (2021). Microscale walkability indicators for fifty-nine European central urban areas: An open-access tabular dataset and a geospatial web-based platform. Data in Brief, 36: 107048. https://doi.org/10.1016/j.dib.2021.107048

[41] Cerin, E., Conway, T.L., Saelens, B.E., Frank, L.D., Sallis, J.F. (2009). Cross-validation of the factorial structure of the neighborhood environment walkability scale (NEWS) and its abbreviated form (NEWS-A). International Journal of Behavioral Nutrition and Physical Activity, 6: 32. https://doi.org/10.1186/14795868-6-32

[42] Moura, F., Cambra, P., Gonçalves, A.B. (2017). Measuring walkability for distinct pedestrian groups with a participatory assessment method: A case study in Lisbon. Landscape and Urban Planning, 157: 282-296. https://doi.org/10.1016/j.landurbplan.2016.07.002

[43] ELSTAT. (2011) Population-Housing Census. Pireaus. https://www.statistics.gr/, accessed on Dec. 29, 2020.
[44] Zhu, W., Sun, Y., Kurka, J., Geremia, C., Engelberg, J.K., Cain, K., Conway, T., Sallis, J.F., Hooker, S.P., Adams, M.A. (2017). Reliability between online raters with varying familiarities of a region: Microscale audit of pedestrian streetscapes (MAPS). Landscape and Urban Planning, $\quad$ 167: 240-248. https://doi.org/10.1016/j.landurbplan.2017.06.014

[45] McCormack, G.R., Koohsari, M.J., Turley, L., Nakaya, T., Shibata, A., Ishii, K., Yasunaga, A., Oka, K. (2021). Evidence for urban design and public health policy and practice: Space syntax metrics and neighborhood walking. Health \& Place, 67: 102277. https://doi.org/10.1016/j.healthplace.2019.102277

[46] Lai, Y., Kontokosta, C.E. (2018). Quantifying place: Analyzing the drivers of pedestrian activity in dense urban environments. Landscape and Urban Planning, 180: 166-178. https://doi.org/10.1016/j.landurbplan.2018.08.018

[47] Xiao, C., Goryakin, Y., Cecchini, M. (2019). Physical activity levels and new public transit: A systematic review and meta-analysis. American Journal of Preventive Medicine, 56(3): 464-473. https://doi.org/10.1016/j.amepre.2018.10.022

[48] Cerin, E., Leslie, E., Toit, L., Owen, N., Frank, L. (2007). Destinations that matter: associations with walking for transport. Health \& Place, 13(3): 713-724. https://doi.org/10.1016/j.healthplace.2006.11.002

[49] Anselin, L. (2010). Local indicators of spatial association-LISA. Geographical Analysis, 27(2): 93-115. https://doi.org/10.1111/j.1538-4632.1995.tb00338.x

[50] GeoDa. (2020). Local Spatial Autocorrelation. https://geodacenter.github.io/workbook/6b_local_adv/la b6b.html\#bivariate-local-morans-i.

[51] Chatterjee, S., Hadi, A.S. (2012). Regression Analysis by Example. Fifth edition., Wiley, Hoboken, New Jersey.

[52] Zhang, M., Kukadia, N. (2005). Metrics of urban form and the modifiable areal unit problem. Transportation Research Record, SAGE Publications Inc, 1902(1): 7179. https://doi.org/10.1177/0361198105190200109 